\title{
A ADMINISTRAÇÃO ESTRATÉGICA DO CAPITAL INTELECTUAL: UM MODELO BASEADO NA CAPACIDADE ABSORTIVA PARA POTENCIALIZAR INOVAÇÃO
}

\section{RESUMO}

O capital intelectual é percebido como um recurso estratégico capaz de ser propulsor da inovação. Neste contexto, sugere-se que o capital intelectual e a capacidade absortiva podem ser influenciadores da capacidade de inovar nas organizações. Este artigo tem como objetivo propor e analisar um Modelo de Administração Estratégica do Capital Intelectual a partir de práticas da capacidade absortiva como potencializadora de inovação. Como método utiliza-se a pesquisa exploratória com abordagem quantitativa e aplicação de questionários para uma amostra de 104 gestores. Na análise dos dados utiliza-se a técnica de modelagem de equações estruturais por meio do Partial Least Squares (PLS) com a análise dos coeficientes de caminho observa-se uma forte relação entre os constructos, o que confirmou as hipóteses da pesquisa. Verificou-se que as práticas organizacionais adotadas para o desenvolvimento do capital intelectual, da capacidade absortiva e da inovação são: a) capacitação constante dos colaboradores; b) programas de sugestões; c) assimilação de novas tecnologias; d) aplicação de conhecimentos técnicos; e) parcerias com órgãos de apoio à inovação. Como contribuições, as evidências encontradas indicam que a capacidade absortiva promove o avanço da inovação, podendo ainda ser possível observar práticas de gestão do capital intelectual a partir de rotinas organizacionais.

Palavras-chave: Capital Intelectual; Capacidade Absortiva; Inovação.

\section{THE STRATEGIC MANAGEMENT OF INTELLECTUAL CAPITAL: A MODEL BASED ON ABSORPTIVE} CAPACITY TO ENHANCE INNOVATION

\section{ABSTRACT}

The intellectual capital is noticed as a strategic resource capable of being propellant of innovation. In this context, it is suggested that the intellectual capital and the absorptive capacity may be influencing of the capacity to innovate in organizations.. This article aims to propose and analyze a Model of Strategic Management of Intellectual Capital from practices of absorptive capacity as enhancement of innovation. It is used as a method an exploratory research with the approach of quantitative and application of questionnaires for a sample of 104 managers. In the data analysis, it is used the technique of structural equation modeling through PLS (Partial Least Squares), with the analysis of path coefficients, we observe a strong relation among the constructs, what confirmed the hypotheses of the research. We verify that the organizational practices adopted for the development of intellectual capital, absorptive capacity and innovation are: a) ongoing training of employees; b) programs of suggestions; c) assimilation of new technologies; d) application of technical knowledge; e) partnerships with supporting innovation institutions. As contributions, the found evidences indicate that the absorptive capacity promotes the advance of innovation, and it's still possible to observe management practices of intellectual capital from organizational routines.

Keywords: Intellectual Capital; Absorptive Capacity; Innovation. 


\section{GESTIÓN ESTRATÉGICA DE CAPITAL INTELECTUAL: UN MODELO BASADO EN LA CAPACIDAD} DE MEJORAR LA INNOVACIÓN DE ABSORCIÓN

\section{RESUMEN}

El capital intelectual se percibe como un recurso estratégico capaz de ser motor de la innovación. En este contexto, se sugiere que el capital intelectual y la capacidad de absorción pueden influir en la capacidad de innovación en las organizaciones. Este artículo tiene como objetivo proponer y analizar un Modelo de Gestión Estratégica del Capital Intelectual de las prácticas de la capacidad de absorción como potenciador de la innovación. A medida que se utiliza un método para la investigación exploratoria con enfoque cuantitativo y cuestionarios a una muestra de 104 gestores. En el análisis de los datos que utiliza la técnica de modelado de ecuaciones estructurales a través de los mínimos cuadrados parciales (PLS) con el análisis de los coeficientes de trayectoria observado una fuerte relación entre las construcciones, lo que confirmó la hipótesis de la investigación. Se encontró que las prácticas de organización para el desarrollo de capital intelectual, la capacidad de absorción y la innovación son: a) la capacitación constante de los empleados; b) programas de sugerencias; c) la asimilación de nuevas tecnologías; d) la aplicación de los conocimientos técnicos; e) asociaciones con organismos de apoyo a la innovación. Como contribuciones, la evidencia encontrada indica que la capacidad de absorción promueve el avance de la innovación y también puede ser posible observar prácticas de gestión del capital intelectual de las rutinas organizativas.

Palabras clave: Capital Intelectual; La capacidad de absorción; La innovación.

\footnotetext{
${ }^{1}$ Doutoranda em Administração na Universidade Nove de julho - UNINOVE. Professora e Pesquisadora do Grupo de Pesquisa de Administração e Ciências Contábeis (GEPACC) na Universidade do Contestado - UNC. Brasil. E-mail: alessandracassol.adm@gmail.com

${ }^{2}$ Doutor em Engenharia de Produção pela Universidade Federal de Santa Catarina - UFSC. Professor da Universidade do Vale do Itajaí - UNIVALI. Brasil. E-mail: claudio.goncalo@univali.br

${ }^{3}$ Mestre em Administração pela Universidade Federal do Rio Grande do Sul - UFRGS. Professor da Universidade do

Vale do Itajaí - UNIVALI. Brasil. E-mail: amsantos.web@gmail.com

${ }^{4}$ Doutor em Economia pelo Université Picardie Jules Verne, França. Professor da Universidade Nove de Julho UNINOVE. Brasil. E-mail: robertoruas@uninove.br
} 


\section{INTRODUÇÃ̃O}

O capital intelectual tem sido cada vez mais discutido dentro do âmbito empresarial, pois está sendo visualizado como fonte de vantagem competitiva, ao ponto que se torna um recurso único e inimitável (Kristandl \& Bontis, 2007; Iencieu \& Matis, 2011). Neste artigo buscou-se compreender a relação entre a administração estratégica do capital intelectual e a inovação, pois, segundo a literatura (Stewart, 1998, 2002; Zanini, 2008; Edvinsson, 2012; Dumay \& Garanina, 2013), a inovação advém de uma gestão adequada do capital intelectual. Para isso, propôs-se um Modelo de Administração Estratégica do Capital Intelectual (MAECI), no qual se sugeriu que a capacidade absortiva pode ser um potencializador desta relação, proporcionando às empresas a capacidade de inovar.

A sobrevivência das empresas pode depender de sua capacidade de inovação a partir do uso de sua inteligência organizacional que, nesta pesquisa, é representado pelo capital intelectual (Carbone, Brandão, Leite \& Vilhena, 2005). Segundo Ienciu e Matis (2011), o capital intelectual pode ser considerado como um dos mais valiosos ativos de uma organização, e, consequentemente, uma poderosa arma competitiva no mundo dos negócios. Para Stewart (1998), o capital intelectual refere-se à soma do conhecimento de todos em uma empresa, o que proporciona vantagem competitiva à organização. Contudo, esta soma de conhecimentos somente torna-se produtiva para a empresa a partir do momento que se transforma em resultados e, neste contexto, podem-se observar ações relacionadas à capacidade absortiva da organização.

Zahra e George (2002) afirmam que a capacidade absortiva pode ser considerada uma dinâmica pertencente à criação e utilização do conhecimento, e pode aumentar a habilidade da empresa de obter e manter uma vantagem competitiva. Segundo os autores, a capacidade absortiva configura-se por um grupo de rotinas e processos organizacionais pelos quais as firmas adquirem, assimilam, transformam e aplicam conhecimento, para produzir uma capacidade organizacional dinâmica.

A administração estratégica do capital intelectual potencializada pela capacidade absortiva da empresa pode ser capaz de impulsionar inovações e, consequentemente, construir diferencial competitivo. Tidd, Besant e Pavitt (2005) referenciam a inovação como o processo de transformar oportunidades em novas ideias, colocando-as amplamente em prática. Analisa-se que o processo de inovar passa pela capacidade absortiva, onde você poderá desenvolver as oportunidades presentes, colocando em prática na organização novos conhecimentos que possam gerar inovações.

Nos últimos dois anos as pesquisas de Edvinsson (2012), Santos, Basso e Kimura (2012), Stoeckicht (2012), Machado e Fracasso (2012), Dumay e Garanina (2013) têm demonstrado uma lacuna teórica relacionada à necessidade de se compreender como fazer uso do capital intelectual para desenvolver a capacidade de inovação. Esta pesquisa procura contribuir com as pesquisas já existentes, potencializando a assimilação sobre como utilizar o recurso estratégico capital intelectual para alavancar a inovação, por meio da capacidade absortiva. Assumese como pressuposto que a capacidade absortiva (CA) pode se tornar um potencializador da inovação, pois conforme as pesquisas de Lane, Koka e Pathak (2006), a CA pode aumentar a velocidade, frequência e magnitude da inovação nas empresas. Assim, a questão que norteia a presente pesquisa é: "Como a administração estratégica do capital intelectual e da capacidade absortiva pode potencializar a inovação?"

A pesquisa possui uma abordagem quantitativa. Como instrumento de coleta de dados utilizou-se a aplicação de um questionário para 149 gestores de uma indústria, obtendo uma amostra de 104 respondentes. Os dados foram analisados com a técnica de modelagem de equações estruturais, por Partial Least Squares (PLS).

Os resultados confirmam que a capacidade absortiva e o capital intelectual influenciam positivamente a geração de inovação. A capacidade da empresa em mobilizar e criar ativos de conhecimento no campo humano, estrutural e relacional fomenta a melhoria e inovação em processos, produtos e gestão organizacional. A pesquisa também demonstrou que a mobilização dos ativos de conhecimento e sua transformação em inovação se justificam, em parte, em razão da capacidade absortiva da empresa. Dessa forma, a pesquisa apresenta como contribuição a comprovação empírica de que o capital intelectual pode ser promovido a partir de práticas relativas à capacidade absortiva que venham potencializar a inovação.

$\mathrm{Na}$ seção seguinte apresenta-se a base teórica para a relação entre Capital Intelectual, Capacidade Absortiva e Inovação. Na sequência, será abordado o método utilizado neste estudo e o desenvolvimento das hipóteses. Após, os resultados, discussão e considerações finais serão descritos.

\section{REVISÃO DE LITERATURA}

\subsection{Capital intelectual como recurso estratégico para as organizações}

O termo capital intelectual passou a ser pesquisado mais intensamente partir da década de 1990, na qual diversos estudos buscaram explicar e mensurar o capital intelectual, sendo pioneiro Sveiby, em 1989. A preocupação das empresas em buscar compreender porque algumas são capazes de estabelecer posições de vantagem competitiva 
sustentável perante suas concorrentes, tem transformado as práticas de gestão organizacional e promovido uma maior inquietação com a capacidade de inovar.

Desse modo, surgem as pesquisas baseadas na perspectiva da Visão Baseada em Recursos (RBV Resource-based View) na qual, conforme Barney (2001), a vantagem competitiva está atrelada à possibilidade de as empresas adquirirem um conjunto de recursos apropriados às demandas do mercado, estando presente na análise dos fatores explicativos do crescimento das organizações. O conhecimento pode ser o recurso distinto da empresa, assim, surge a teoria baseada no conhecimento (KBV - Knowledge-based view), que pode ser vista como uma extensão da teoria baseada em recursos ou como uma extensão das áreas de aprendizado organizacional e da teoria das organizações (Eisenhardt \& Santos, 2002; Acedo, Barroso \& Galan, 2006). Entre as várias áreas de estudos que existem sobre a gestão do conhecimento nas organizações, há uma que enfoca o capital intelectual. Sveiby (1997) e Edvinsson e Malone (1998) são os representantes desta corrente e abordam a existência de ativos chamados de intangíveis, que proporcionam o desenvolvimento e valorização da organização baseada nestes ativos.

Para Ienciu e Matis (2011), o capital intelectual pode ser considerado como um dos mais valiosos ativos de uma organização, e, consequentemente, uma poderosa arma competitiva no mundo dos negócios. Aborda-se nesta pesquisa que o capital intelectual refere-se à soma do conhecimento de todos em uma empresa, o que proporciona vantagem competitiva à organização (Stewart, 1998).

O capital intelectual possui diferentes dimensões e, conforme Ienciu e Matis (2011), contém três elementos principais: o capital humano, capital relacional e capital estrutural. O capital humano representa todos os recursos humanos envolvidos em um processo (funcionários, clientes, fornecedores, investidores, ou seja, os stakeholders da organização). O segundo elemento, considerado o capital estrutural, inclui a cultura organizacional, o capital de infraestrutura e os processos. Enquanto o terceiro elemento, o capital relacional, reflete as relações ou conexões que a organização possui com seus clientes, fornecedores ou outros usuários de suas informações contábeis-financeiras.

A partir da perspectiva da importância de as organizações potencializarem o capital intelectual para construir a capacidade de inovar, esta pesquisa busca compreender e demonstrar como as organizações podem fazer uso do capital intelectual e direcioná-lo para a geração de inovações. $\mathrm{O}$ modelo proposto valoriza a utilização do conhecimento interno ou externo à organização como potencializador por meio da capacidade absortiva.

\subsection{Capacidade absortiva como desafio na gestão das organizações}

Os autores Cohen e Levinthal, em 1989, foram os primeiros a abordarem o termo capacidade absortiva, que significa a capacidade de a empresa identificar, assimilar e explorar a informação do ambiente. A capacidade absortiva é um dos componentes das capacidades dinâmicas, relacionado à habilidade de a organização reconhecer o valor de novas informações externas, assimilando-as e aplicando-as (Wang \& Ahmed, 2007). Entretanto, esta habilidade é dependente do nível de conhecimento anterior que a empresa possui. Zahra e George (2002) afirmam que a capacidade absortiva se configura por um grupo de rotinas e processos organizacionais pelos quais as firmas adquirem, assimilam, transformam e aplicam conhecimento, para produzir uma capacidade organizacional dinâmica.

As relações inter-organizacionais, como redes de empresas e alianças estratégicas, influenciam de maneira distinta o desempenho das empresas, isso em virtude dos recursos singulares e dos níveis de apropriação dos recursos gerados pela rede em função das características das firmas e da capacidade absortiva de cada parceiro (Zen; Dalmoro; Fensterseifer \& Wegner, 2013). Ou seja, a capacidade absortiva pode ser dinâmica e pertencente à criação e utilização do conhecimento, e pode aumentar a habilidade da empresa em obter e manter uma vantagem competitiva. Infere-se que ela é dependente do nível de desenvolvimento do conhecimento que a organização possui, neste artigo assume-se que as práticas organizacionais podem ser aprimoradas nas organizações, conforme o modelo de pesquisa proposto.

A capacidade absortiva se divide em capacidade absortiva potencial e capacidade absortiva realizada. $\mathrm{Na}$ capacidade absortiva potencial tem-se uma bagagem de conhecimento que foi adquirida e assimilada, mas que se encontra em um nível "adormecido", até que exista um real uso para esse conhecimento. A capacidade absortiva realizada preocupa-se com a transformação e aplicação do que foi previamente adquirido, proporcionando uma vantagem competitiva a ser desenvolvida em curto ou médio prazo (Zahra \& George, 2002). A capacidade absortiva é composta por quatro principais dimensões, as quais são incorporadas às duas divisões da capacidade absortiva, sendo a aquisição e assimilação do novo conhecimento integrante da capacidade absortiva potencial. E a transformação e a aplicação (exploitation) que compõem a capacidade absortiva realizada.

Segundo Murovec e Prodan (2009), a cooperação em inovação está relacionada à capacidade absortiva potencial, pois se refere às atividades direcionadas a inovações desenvolvidas com diferentes 
tipos de parceiros, como fornecedores, clientes, concorrentes, consultores e universidades.

\subsection{Inovação como diferencial competitivo}

A pesquisa abordando o termo inovação tem crescido nos últimos anos, o que pode estar relacionado à compreensão por parte das empresas que a inovação se expressa como um diferencial competitivo. A literatura especializada (ver Rogers, 1962, Utterback, 1971, Beije, 1998, Freeman \& Soete, 2008, Tidd, Bessant \& Pavitt, 2008) tem conceituado o termo inovação, porém a maioria dos autores apresenta conceitos de inovação destacando elementos muito próximos aos apresentados por Schumpeter (1997).

Nesta pesquisa assume-se o conceito de inovação proposto por Tidd, Bessant e Pavitt (2005), ou seja, a inovação é o processo de transformar oportunidades em novas ideias, colocando-as amplamente em prática. Compreende-se que o processo de inovar está relacionado com a capacidade absortiva da empresa, a qual poderá desenvolver o conhecimento presente internamente e aprimorá-lo com novos conhecimentos advindos de fontes externas.

Tidd, Bessant e Pavitt (2008) seguem os princípios de Schumpeter (1997), e apontam que a inovação pode assumir quatro formas: inovação de produto (envolve mudança nas características ou na estrutura dos produtos ou serviços que a empresa oferece); inovação de processo (considera a mudança na forma em que os produtos/serviços são criados e entregues); inovação de posição (trata das mudanças no contexto em que produto/serviços são introduzidos) e inovação de paradigma (refere-se às mudanças nos modelos mentais subjacentes que orientam o que a empresa faz).
Contudo, somente a estrutura propícia para a inovação não é suficiente para que seja caracterizada como inovadora, é necessário uma série de componentes integrados para criar e reforçar o tipo de ambiente apropriado para a geração de inovação. Desse modo, a empresa inovadora, segundo Tidd, Bessant e Pavitt (1997), é formada por dez componentes que podem ser interligados internamente para atingir um bom desempenho: visão compartilhada e liderança; estrutura apropriada; indivíduos-chave; grupos de trabalho efetivo; desenvolvimento individual contínuo; comunicação extensiva; alto envolvimento em inovação; foco no cliente; ambiente criativo; aprendizagem organizacional. Assim, uma empresa inovadora é caracterizada como empresa que, durante determinado período analisado, desenvolveu estratégias inovadoras e implantou produtos e processos, modelos de gestão, de marketing e de negócios, ou, ainda, uma combinação destes (Manual de Oslo, 2012).

Compreende-se que as empresas que conseguem utilizar o seu capital intelectual, desenvolvendo-o por meio da capacidade absortiva, possuem maiores probabilidades de inovarem e, consequentemente, criar vantagem competitiva e recursos valiosos e inimitáveis.

\section{DESENVOLVIMENTO CONCEITUAL E HIPÓTESES}

Buscando compreender melhor as hipóteses derivativas da pesquisa e as correlações entre os constructos propôs-se o Modelo de Administração Estratégica do Capital Intelectual, Figura 1, que busca verificar a existência, ou não, de relações entre os constructos pesquisados. 


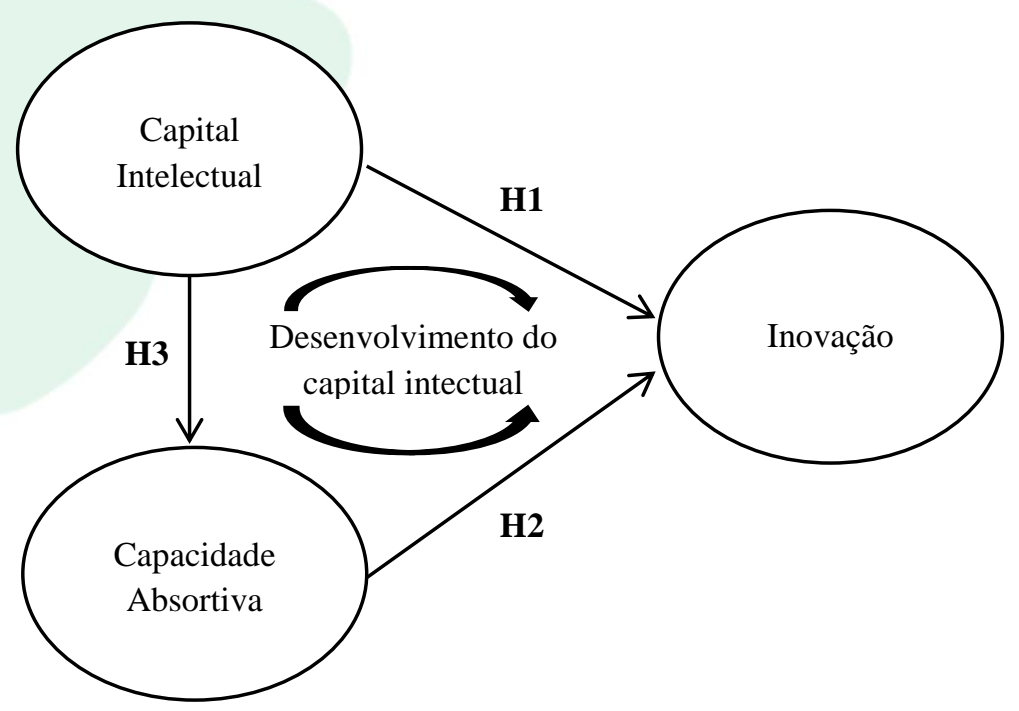

Figura 1 - Modelo de Administração Estratégica do Capital Intelectual (MAECI) Fonte: elaborado pelos autores.

A hipótese $\mathrm{H} 1$ preconiza a existência de relação entre o constructo capital intelectual e inovação. Sugere-se que organizações que possuem ações direcionadas para o desenvolvimento das três dimensões do capital intelectual tornam-se mais propícias à inovação, tornando-se esta uma consequência da gestão efetiva do capital intelectual.

Propõe-se que o capital intelectual pode se tornar o ponto de partida para a inovação, pois os ativos intangíveis de uma organização podem valorizar e fornecer credibilidade, além de determinar a capacidade de inovar e aprender, sendo necessário que as empresas façam uma administração estratégica de seu acervo intelectual (Almeida, 2008). Observa-se que os esforços das firmas brasileiras para melhorar sua capacidade de inovar se estruturam nos três eixos do capital intelectual: capital humano, capital relacional e capital interno, ou capital estrutural (Santos, Basso \& Kimura 2012).

Dessa forma, a administração estratégica do capital intelectual pode possuir influência sobre o processo de inovação das organizações, pois por meio deste é possível direcionar esforços e conhecimentos para o desenvolvimento da capacidade de inovar. Assim, a primeira hipótese tem como base os estudos dos autores Subramaniam e Youndt (2005), Almeida (2008), Stoeckicht (2012), Santos, Basso e Kimura (2012), para propor que:

H1: Capital intelectual está relacionado positivamente com a inovação.

A hipótese $\mathrm{H} 2$ defende a existência da relação entre o constructo capacidade absortiva e inovação. Propõe-se que as organizações que possuem a capacidade de adquirir, assimilar, transformar e aplicar conhecimentos possuem maior vantagem competitiva, uma vez que a capacidade absortiva configura-se como a habilidade da organização de avaliar o valor de novos conhecimentos, assimilar essas informações e aplicálas na empresa, e, por meio desta aplicação, desenvolve-se o processo de inovação.

O conhecimento organizacional necessita ser compartilhado e potencializado em um processo dinâmico para que, entre outros resultados, possa conduzir à geração de inovações organizacionais (Flatten, Engelen, Zahara \& Brettel, 2011). Este processo de compartilhamento perpassa pela administração estratégica dos recursos e conhecimentos atuais que a organização detém e os novos conhecimentos adquiridos em suas relações internas e externas. Observa-se que por intermédio da capacidade absortiva uma empresa pode lidar mais rapidamente com novos projetos, alocando facilmente o pessoal em equipes e reduzindo lacunas de conhecimento entre equipes e organizações, podendo potencializar os conhecimentos existentes para desenvolver inovações (Liu, 2012).

Corroborando, Dias e Pedroso (2012) observam que um dos fatores que contribui para a inovação está relacionado à capacidade absortiva e que este é um dos fatores influenciadores da capacidade de inovar das organizações. Sugere-se que por meio do desenvolvimento da capacidade absortiva a organização possua um potencial maior de inovação. Desse modo, suportado pelas pesquisas dos autores Malek e Breggar (2001), Hitt, Ireland e Hoskisson (2008), Murovec e Prodan (2009), Flatten, Engelen, Zahara e Brettel (2011), Liu (2012), Dias e Pedroso (2012), propõe-se a segunda hipótese: 
H2: Capacidade absortiva está relacionada positivamente com a inovação.

A hipótese $\mathrm{H} 3$ preconiza a existência de relação entre o constructo capital intelectual e a capacidade absortiva. Considera-se que organizações que possuem uma administração estratégica das três dimensões do capital intelectual (capital humano, estrutural e relacional) possam desenvolver a capacidade absortiva buscando o constante aprimoramento dos seus conhecimentos e um melhor desempenho.

O efeito combinado dos níveis de capacidade absortiva e de capital relacional, caracterizado pela soma dos recursos atuais e potenciais que existem e estão disponíveis em uma rede de relacionamentos, auxilia a compreender as diferenças de desempenho das empresas (Wegner \& Maehler, 2010). Sugere-se que o processo de gestão do capital intelectual (humano, estrutural e relacional) está relacionado ao desenvolvimento da capacidade absortiva da organização. Observa-se que as organizações passam a utilizar os seus recursos humanos, estruturais e sua rede de relacionamentos para buscar melhor desempenho organizacional, o que é potencializado por meio da construção da capacidade absortiva.

Outros estudos (ver Machado \& Fracasso, 2012) buscam compreender a relação entre o capital intelectual, capacidade absortiva e inovação. Pressupõe-se que diferentes recursos internos possam influenciar de forma diferente as dimensões da capacidade absortiva, e, posteriormente, levar a resultados diferentes de inovação e desempenho. Dessa forma, compreende-se que a capacidade absortiva é mediadora entre o compartilhamento de conhecimento, neste estudo abordado como capital intelectual, e o desempenho das organizações (Nodari, 2013).

Conforme proposto por Wegner e Maehler (2010), Machado e Fracasso (2012), Nodari (2013) verifica-se no ambiente organizacional a relação entre a capacidade absortiva e o capital intelectual. Sendo assim, propõe-se a terceira hipótese da pesquisa:

H3: Capital intelectual está relacionado positivamente com a capacidade absortiva.

Com base nas hipóteses propostas define-se o método da pesquisa, que conduzirá os resultados.

\section{MÉTODO}

Esta pesquisa se caracteriza como estudo quantitativo e descritivo à medida que visa observar as relações de um fenômeno específico, apontando seu funcionamento e estabelecendo relações entre as variáveis (Malhotra, 2012), buscando estabelecer aspectos causais finais.

\subsection{Variáveis do estudo}

As variáveis que compreendem este estudo referem-se aos constructos pesquisados: capital intelectual, capacidade absortiva e inovação. Assim, foram utilizados três questionários de diferentes pesquisas cujo propósito era pesquisar cada constructo individualmente, dessa forma, o intuito nesta pesquisa foi de realizar um instrumento que fosse capaz de investigar os três constructos de forma unificada.

O questionário foi então adaptado a partir de Gracioli, Godoy, Lorenzett \& Godoy (2012) para mensurar capital intelectual; Camisón e Forés (2010) para capacidade absortiva; e Stoeckicht (2012) para inovação. Como as questões eram oriundas de estudos empíricos aplicados em ambientes organizacionais distintos do estudado, foi necessário verificar se todas as variáveis dos instrumentos originais se aplicariam à realidade organizacional pesquisada. Assim, realizou-se pré-testes por meio de entrevistas com os diretores e, posteriormente, aplicação do questionário a seis gestores (gerentes), os quais o responderam visando adequá-lo ao contexto da pesquisa. Como resultado, ajustes semânticos e exclusão de variáveis foram necessários para a adequação do instrumento de pesquisa.

O questionário inicial após os pré-testes possuía 47 variáveis, as quais foram aplicadas durante a pesquisa utilizando escala do tipo Likert com cinco pontos, variando entre "discordo totalmente" e "concordo totalmente". Após a realização dos testes estatísticos e da depuração das variáveis o instrumento final permaneceu com 23 variáveis, conforme Quadro 1. 


\begin{tabular}{|c|c|c|}
\hline CONSTRUCTO & DIMENSÃO & VARIÁVEIS E MEDIDAS \\
\hline \multirow{3}{*}{ Capital Intelectual } & Capital Humano & $\begin{array}{l}\text { CH2 Colaboradores são estimulados a serem sempre criativos e terem } \\
\text { iniciativa. } \\
\text { CH3 É elevado o nível de escolaridade/graduação dos colaboradores. } \\
\text { CH6 Todos os colaboradores são capacitados para desenvolver suas } \\
\text { funções. } \\
\text { CH8 As competências dos colaboradores permitem os mesmos } \\
\text { inovarem em suas tarefas. }\end{array}$ \\
\hline & Capital Estrutural & $\begin{array}{l}\text { CE2 Sugestões dos colaboradores são implementadas quando } \\
\text { pertinentes. } \\
\text { CE3 Existe melhoria nas capacidades técnicas dos processos de } \\
\text { produção. } \\
\text { CE4 As perdas e desperdícios têm sido reduzidos. }\end{array}$ \\
\hline & Capital Relacional & $\begin{array}{l}\text { CR4 Satisfação dos clientes em relação a preço, qualidade e prazos tem } \\
\text { sido adequada. } \\
\text { CR5 A empresa tem uma ótima reputação e parceria com clientes e } \\
\text { fornecedores. } \\
\text { CR6 A empresa identifica as necessidades dos clientes. }\end{array}$ \\
\hline \multirow[t]{2}{*}{$\begin{array}{c}\text { Capacidade } \\
\text { Absortiva }\end{array}$} & $\begin{array}{c}\text { Capacidade } \\
\text { Absortiva } \\
\text { Potencial }\end{array}$ & $\begin{array}{l}\text { CAP1 A empresa tem capacidade de captar informação e conhecimento } \\
\text { relevante, contínuo e atualizado sobre os concorrentes atuais e } \\
\text { potenciais. } \\
\text { CAP2 A empresa tem orientação para a gestão esperando para ver o que } \\
\text { acontece, em vez de preocupação e orientação para monitorar o } \\
\text { ambiente e acompanhar as tendências de forma contínua e descobrir } \\
\text { novas oportunidades a serem exploradas de forma proativa. } \\
\text { CAP3 Considerando a frequência e importância da cooperação com as } \\
\text { organizações de P\&D - universidades, escolas de negócios, institutos } \\
\text { tecnológicos, etc. - a empresa é um membro ou patrocinador da criação } \\
\text { de conhecimento e inovações. }\end{array}$ \\
\hline & $\begin{array}{c}\text { Capacidade } \\
\text { Absortiva } \\
\text { Realizada }\end{array}$ & $\begin{array}{l}\text { CAR4 A empresa tem capacidade de assimilar novas tecnologias e } \\
\text { inovações que são úteis ou têm potencial comprovado. } \\
\text { CAR5 A empresa tem capacidade de usar o nível de conhecimento, } \\
\text { experiência e competências na interpretação e assimilação de novos } \\
\text { conhecimentos dos funcionários. } \\
\text { CAR6 A empresa tem capacidade para desenvolver programas de } \\
\text { gestão do conhecimento, garantindo a capacidade da empresa para } \\
\text { entender e analisar cuidadosamente conhecimento e tecnologia de } \\
\text { outras organizações. }\end{array}$ \\
\hline \multicolumn{2}{|c|}{ Inovação } & $\begin{array}{l}\text { INOV3 A empresa desenvolve novos produtos. } \\
\text { INOV4 A empresa desenvolve melhorias nos produtos existentes. } \\
\text { INOV5 A empresa criou ou melhorou produtos com base em ideias de } \\
\text { colaboradores, clientes ou fornecedores. } \\
\text { INOV7 A empresa melhora os seus atuais métodos de produção. } \\
\text { INOV8 A empresa busca a aplicação de novas tecnologias em seus } \\
\text { sistemas de produção. } \\
\text { INOV10 Existe a promoção de uma cultura organizacional voltada para } \\
\text { a inovação. } \\
\text { INOV11 A empresa promove o comportamento empreendedor e } \\
\text { inovador em suas diversas unidades/áreas/departamentos. }\end{array}$ \\
\hline
\end{tabular}

Quadro 1 - Variáveis e medidas finais dos construtos pesquisados

Fonte: elaborado pelos autores. 


\subsection{Universo de pesquisa}

A população foi composta por gestores de um grupo industrial do setor de celulose e papel que atua no mercado há 72 anos em nível nacional e internacional, com unidades de negócios distribuídas em quatro estados brasileiros. Participaram da pesquisa 149 respondentes, sendo 27 gerentes, 78 coordenadores e 44 supervisores, distribuídos em todas as unidades de negócio da empresa. Obteve-se um retorno de 104 respondentes, o que configura um percentual de participação de $70 \%$.

\subsection{Estratégia de coleta de dados}

Para a obtenção dos dados foi realizado um survey com corte transversal e utilização de questionários estruturados disponibilizados para preenchimento via web em um site especializado em coleta de dados. Após autorização da empresa pesquisada realizou-se contato telefônico com os gestores participantes da amostra, com o intuito de explicar a pesquisa, também houve a participação em reuniões com os gestores. Posteriormente, o questionário foi enviado, por e-mail, para os 149 respondentes.

\subsection{Critérios de análise dos dados}

Para a análise dos dados utilizou-se o método estatístico de Análise de Modelos de Equações Estruturais (MEE), pelo método de Partial least squares (PLS), por meio do software SmartPLS 2.0. A MEE-PLS nos permite analisar a relação entre múltiplas variáveis simultaneamente, sejam elas latentes ou observadas (Hair, Hult, Ringle \& Sarstedt, 2013, Malhotra, 2012). Na pesquisa foram avaliadas a confiabilidade, a validade convergente e a validade discriminante de cada variável. Quanto à escolha pela utilização do software SmartPLS justificou-se, pois, segundo Hair, Ringle e Sarstedt (2011), ele fornece estimativas e parâmetros que maximizam a variância explicada (valores de $\mathrm{R}^{2}$ ) dos modelos estudados. Outra justificativa para a utilização do método PLS (Partial Least Squares) é a ausência de suposições sobre a distribuição dos dados, como normalidade e uso de escalas intervalares (Mateos-Aparicio, 2011).

Com base nas hipóteses propostas e definidos os tratamentos dos dados quantitativos apresenta-se, a seguir, a análise, juntamente com os resultados alcançados.

\section{RESULTADOS}

O mercado da indústria de papel e papelão ondulado é considerado tradicional e possui uma tecnologia relativamente acessível e cada vez mais globalizada. Sendo assim, a globalização permite que países, antes sem expressão nesse mercado, participem como produtores competitivos, alterando o perfil da indústria, o que faz com que o setor seja caracterizado por intensa competição por mercados e por investimentos, porém não por inovações ou diferenciais competitivos.

O segmento de celulose e papel conta com a participação de 220 empresas com atividade em 540 municípios, localizados em 18 estados brasileiros, gerando 128 mil empregos diretos e 640 mil empregos indiretos em 2012. Além disso, apresentou um saldo comercial de US\$ 4,7 bilhões em 2012 (Associação Brasileira de Celulose e Papel, 2013). Dessa forma, verifica-se que o setor ao qual a empresa em estudo pertence possui relevância na economia brasileira, sendo utilizado como um termômetro do crescimento econômico do país.

Os gestores participantes da pesquisa fazem parte de uma indústria de grande porte do setor de papel e papelão ondulado que atua no mercado há 72 anos em nível nacional e internacional. A escolha por esta amostra justificou-se em razão de a empresa possuir inúmeros programas de gestão para inovação, que propiciaram uma atuação focada na gestão do capital intelectual, com o intuito de desenvolver inovações, demonstrando, assim, ser um campo empírico relevante para a pesquisa. O objetivo da empresa é disseminar a cultura da inovação por meio da geração de ideias, da capacitação de colaboradores e da difusão da inovação aberta; os programas existentes abrangem todas as unidades de negócio da empresa e contam com a participação de colaboradores, de universidades, de instituições científico-tecnológicas, de fornecedores e de clientes.

Obteve-se um retorno de 104 gestores durante a pesquisa, sendo estes parte do nível tático da empresa que está em relação direta e constante com os colaboradores e diretores, também se tornando os responsáveis pela disseminação de uma cultura de inovação. Na Tabela 1 apresenta-se o percentual de frequência dos respondentes em relação ao cargo que ocupam na empresa. 
A Administração Estratégica do Capital Intelectual: Um Modelo Baseado na Capacidade Absortiva para Potencializar Inovação

Tabela 1 - Distribuição dos respondentes quanto à função exercida dentro da empresa

\begin{tabular}{|l|c|c|c|}
\hline \multicolumn{1}{|c|}{ Função } & Frequência & Porcentual & Porcentagem acumulativa \\
\hline Supervisor & 29 & 27,9 & 27,9 \\
\hline Coordenador & 58 & 55,8 & 83,7 \\
\hline Gerente & 17 & 16,3 & 100,0 \\
\hline Total & $\mathbf{1 0 4}$ & $\mathbf{1 0 0 , 0}$ & \\
\hline
\end{tabular}

Fonte: dados da pesquisa.

A primeira avaliação realizada com os dados foi o teste de normalidade. Segundo Maroco (2007), faz-se necessário que a distribuição amostral seja do tipo normal, pois é um dos requisitos de uma série de testes paramétricos. Para verificar a normalidade dos dados foi feito o teste de Kolmogorov-Smirnov. Após o teste verificou-se que os dados não apresentam normalidade, possuindo um p-value de 0,000, assim, reforçando a escolha pelo método PLS.

\subsection{Análise fatorial confirmatória}

A primeira etapa realizada foi a utilização do método de estimação do modelo de mensuração, o qual mede a relação latente e manifesta associada às variáveis observadas. Na primeira estrutura de análise gerada com todas as variáveis onde se verificou se os betas dos caminhos entre as variáveis latentes e as manifestas eram valores maiores que 0,7 , conforme Hair, Hult, Ringle e Sarstedt (2013) sugerem. Dessa forma, optou-se por retirar as variáveis mensuráveis que possuíam betas menores de 0,7, mantendo os Average Variance Extracted (AVEs) maiores que 0,5, atendendo à pressuposição de Hair, Hult, Ringle e Sarstedt (2013). Após os testes foram retiradas 14 variáveis do constructo capital intelectual, 5 variáveis do constructo capacidade absortiva e 3 variáveis do constructo inovação, obtendo, assim, a estrutura de análise final, conforme Figura 2. 
A Administração Estratégica do Capital Intelectual: Um Modelo Baseado na Capacidade Absortiva para Potencializar Inovação

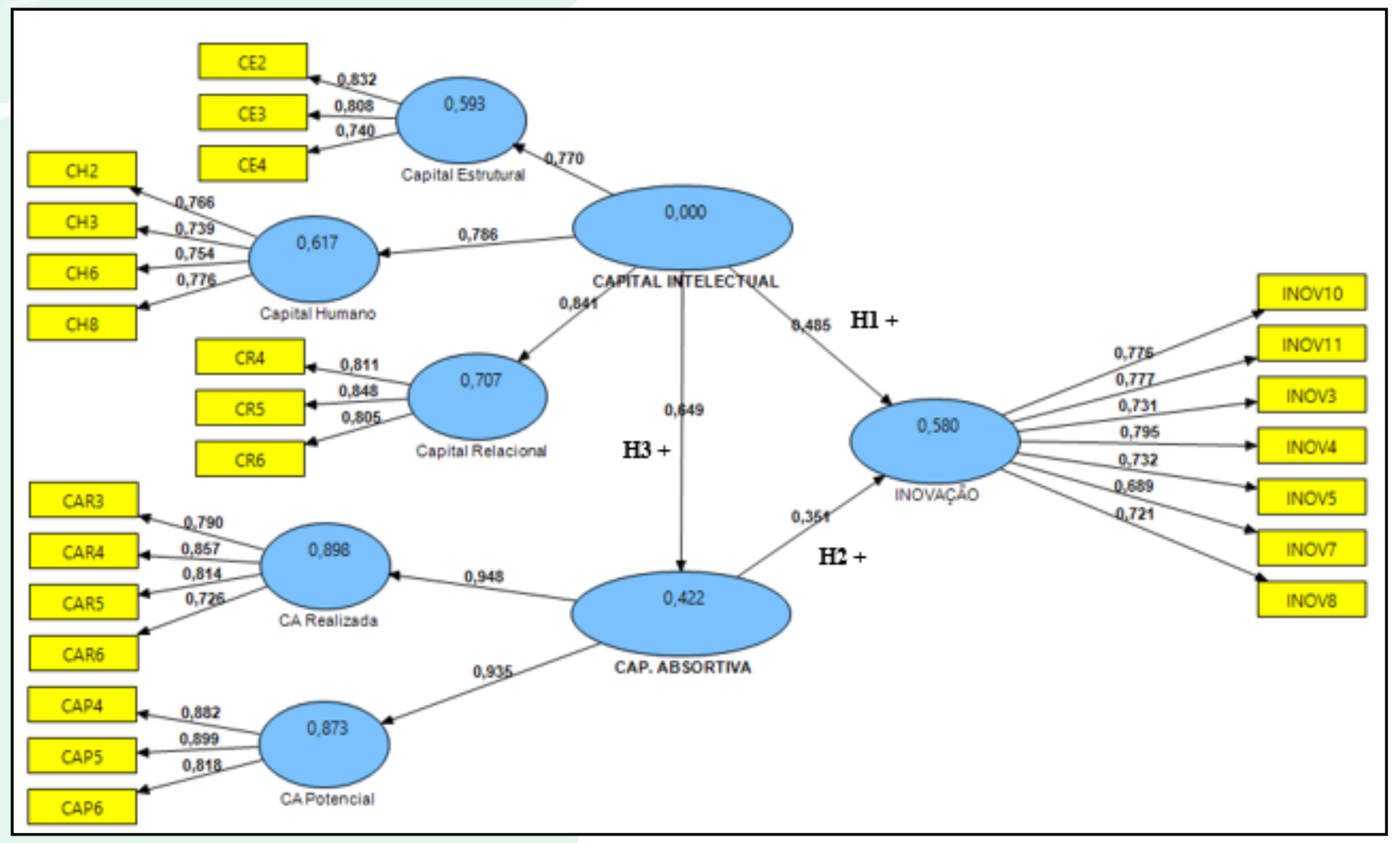

Figura 2 - Estrutura de análise quantitativa final Fonte: dados da pesquisa.

A segunda etapa das análises refere-se à realização da validade discriminante, que busca verificar se a medida em questão não está relacionada indevidamente com indicadores de constructos distintos (Hair, Babin, Money \& Samouel, 2005). Nesta pesquisa utiliza-se o critério de Fornell-Larcker para a avaliação da validade, pois tem como objetivo comparar as raízes quadradas dos valores de AVEs de cada constructo com as correlações (de Pearson) entre os constructos (variáveis latentes) (Henseler, Ringle \& Sinkovics, 2009, Hair, Ringle \& Sarstedt, 2011). A validade discriminante indica até que ponto as variáveis latentes são independentes umas das outras (Hair, Hult, Ringle \& Sarstedt, 2013). Conforme Tabela 2, verifica-se que todos os valores de AVE são maiores que as demais correlações apresentadas, o que indica uma validade discriminante entre os constructos.

Tabela 2 - Correlação de Pearson e a raiz quadrada da AVE das variáveis latentes dos construtos de primeira ordem

\begin{tabular}{|l|c|c|c|c|c|c|}
\hline & $\begin{array}{c}\text { CA } \\
\text { Potencial }\end{array}$ & $\begin{array}{c}\text { CA } \\
\text { Realizada }\end{array}$ & $\begin{array}{c}\text { Capital } \\
\text { Estrutural }\end{array}$ & $\begin{array}{c}\text { Capital } \\
\text { Humano }\end{array}$ & $\begin{array}{c}\text { Capital } \\
\text { Relacional }\end{array}$ & Inovação \\
\hline CA Potencial & $\mathbf{0 , 8 6 6 9}$ & & & & & \\
\hline CA Realizada & 0,7726 & $\mathbf{0 , 7 9 7 9}$ & & & & \\
\hline Capital Estrutural & 0,4688 & 0,3582 & $\mathbf{0 , 7 9 4 2}$ & & & \\
\hline Capital Humano & 0,5442 & 0,5372 & 0,3652 & $\mathbf{0 , 7 5 9 0}$ & & \\
\hline Capital Relacional & 0,5021 & 0,4842 & 0,5529 & 0,4604 & $\mathbf{0 , 8 2 1 5}$ & \\
\hline Inovação & 0,6163 & 0,6364 & 0,5538 & 0,5775 & 0,5693 & $\mathbf{0 , 7 4 6 7}$ \\
\hline
\end{tabular}

Fonte: Dados da pesquisa.

*Os valores em negrito (na diagonal) são a raiz quadrada da AVE, os demais valores são as correlações entre as variáveis. 
A confiabilidade e validade convergente dos constructos foram avaliadas por meio da consistência interna dos constructos utilizando o Alfa de Cronbach e a Confiabilidade Composta (CC). O coeficiente de Alfa de Cronbach varia de 0 a 1, onde um valor de 0,6 ou menor geralmente indica uma confiabilidade de coerência interna insatisfatória (Malhotra, 2012). A confiabilidade composta deve apresentar valores superiores a 0,6 para ser considerada aceitável (Nunnally \& Bernstein, 1994). Conforme Tabela 3, observa-se que os valores de confiabilidade composta apresentam-se dentro do adequado para todos os itens. O valor de Alfa Cronbach também se apresentou satisfatório para todos os constructos.

Tabela 3 - Análise de confiabilidade dos construtos de $1^{\mathrm{a}}$ e $2^{\mathrm{a}}$ ordem

\begin{tabular}{|c|l|c|c|c|c|}
\hline $\begin{array}{c}\text { CONSTRUCTOS } \\
\mathbf{2}^{\mathbf{0}} \text { ORDEM }\end{array}$ & \multicolumn{1}{|c|}{$\begin{array}{c}\text { CONSTRUCTOS } \\
\mathbf{1}^{\mathbf{0}} \text { ORDEM }\end{array}$} & Itens & ALFA & CC & AVE \\
\hline \multirow{2}{*}{ CA } & CA Potencial & 3 & 0,834 & 0,901 & 0,752 \\
\cline { 2 - 6 } & CA Realizada & 4 & 0,808 & 0,875 & 0,637 \\
\hline \multirow{3}{*}{ CI } & Capital Estrutural & 3 & 0,706 & 0,836 & 0,631 \\
\cline { 2 - 6 } & Capital Humano & 3 & 0,756 & 0,845 & 0,576 \\
\cline { 2 - 6 } & Capital Relacional & 7 & 0,759 & 0,862 & 0,675 \\
\hline & Inovação & & 0,898 & 0,557 \\
\hline
\end{tabular}

Fonte: Dados da pesquisa.

Obs.: a) A coluna Itens indica o número de variáveis de cada construto das escalas finais (purificadas); b) Alfa indica o valor da estatística Alfa de Cronbach; c) CC indica o valor da confiabilidade composta; d) AVE indica o valor da variância média extraída.

A validade convergente mede até que ponto a escala se correlaciona positivamente com outras medidas do mesmo constructo (Malhotra, 2012), a qual também precisa ser verificada. Para se obter um grau de validade convergente elevado é necessário que o valor de AVE seja de 0,50 ou maior. Isso significa que a variável latente explica mais da metade da variância dos seus indicadores (Tabachnick \& Fidell, 2001). Observa-se na Tabela 3 que todos os constructos alcançaram a validade convergente, apresentando valores acima de 0,50 .

\subsection{Análise do modelo estrutural}

A avaliação do modelo estrutural foi realizada em duas etapas. Na primeira etapa, foram avaliados os coeficientes de Pearson $\left(\mathrm{R}^{2}\right)$, que indicam a porção da variância das variáveis endógenas explicadas pelo modelo estrutural. Na área das ciências sociais, Cohen (1992) sugere que valores de $\mathrm{R}^{2}$ com limites em $2 \%, 13 \%$ e $26 \%$, podem ser considerados, respectivamente, como pequeno, médio ou grande efeito. Como observado na Tabela 4 , todos os valores de $\mathrm{R}^{2}$ foram superiores a $26 \%$, indicando um efeito grande, o que é um bom indicador para o modelo.

$\mathrm{Na}$ segunda etapa, a avaliação do modelo estrutural foi realizada verificando-se a relevância preditiva e o tamanho do efeito (Hair, Hult, Ringle \& Sarstedt, 2013). A relevância preditiva $\left(\mathrm{Q}^{2}\right)$ ou indicador de Stone-Geisser que avalia a precisão do modelo ajustado, onde se deve ter como critério de avaliação valores maiores de zero (Hair, Hult, Ringle \& Sarstedt, 2013). O tamanho do efeito ( $\left.\mathrm{f}^{2}\right)$ ou indicador de Cohen, valor que é obtido pela inclusão e exclusão de constructos do modelo (um a um), valores entre 0,02 e 0,15 são considerados pequenos, valores entre 0,15 e 0,35 são considerados médios e acima de 0,35 são considerados grandes (Hair, Hult, Ringle \& Sarstedt, 2013). Observase, na Tabela 4, que a relevância preditiva $\left(\mathrm{Q}^{2}\right)$ apresentou valores maiores que zero, e o tamanho do efeito $\left(\mathrm{f}^{2}\right)$ foi, em sua maioria, grande, apresentando somente três constructos com médio efeito. 
A Administração Estratégica do Capital Intelectual: Um Modelo Baseado na Capacidade Absortiva para Potencializar Inovação

Tabela 4 - Relevância Preditiva $\left(\mathrm{Q}^{2}\right)$ e Tamanho do Efeito $\left(\mathrm{f}^{2}\right)$ dos construtos

\begin{tabular}{|l|c|c|}
\hline & $\mathbf{Q}^{\mathbf{2}}$ & $\mathbf{F}^{\mathbf{2}}$ \\
\hline CA Potencial & 0,655847 & 0,484117 \\
\hline CA Realizada & 0,582682 & 0,395517 \\
\hline Capacidade Absortiva & 0,230627 & 0,474365 \\
\hline Capital Estrutural & 0,386742 & 0,275834 \\
\hline Capital Humano & 0,361753 & 0,296317 \\
\hline Capital Relacional & 0,492978 & 0,343846 \\
\hline Capital Intelectual & 0,257207 & 0,257207 \\
\hline Inovação & 0,305755 & 0,405250 \\
\hline
\end{tabular}

Fonte: Dados da pesquisa.

$\mathrm{O}$ indicador de Goodnesss-of-fit, outrora bastante comum em pesquisas com PLS, tem sido apontado como inócuo em seu poder estatístico para diferenciar a qualidade de um modelo estrutural (Henseler \& Sarstedt, 2013, Hair, Hult, Ringle \& Sarstedt, 2013) e não foi utilizado nesta pesquisa.

Dessa forma, com base nas análises dos dados quantitativos verificam-se, a seguir, as hipóteses propostas para esta pesquisa.

\subsection{Testes de hipóteses}

Com a conclusão dos testes estatísticos demonstrou-se os índices de ajuste do modelo final com base nas relações previstas e os resultados alcançados durante a pesquisa. Na Tabela 5 observa-se o $\beta$ na relação entre os constructos pesquisados.

$\mathrm{Na}$ Figura 2 (apresentada anteriormente) verificou-se os coeficientes de caminho do modelo estrutural, os quais também podem ser interpretados como coeficientes beta- $\beta$ (coeficientes de regressão padronizados) de mínimos quadrados. Eles podem ser utilizados para uma comparação direta entre coeficientes e seus poderes relativos de explicação da variável dependente (Hair, Babin, Money \& Samouel, 2005).

Tabela 5 - Parâmetros da estrutura quantitativa da pesquisa

\begin{tabular}{|l|c|c|}
\hline \multicolumn{1}{|c|}{ Relação } & $\boldsymbol{\beta}$ & Valor t \\
\hline H1: Capital intelectual - Inovação & 0,485 & 4,943 \\
\hline H2: Capacidade Absortiva - Inovação & 0,351 & 4,052 \\
\hline H3: Capital intelectual - Capacidade Absortiva & 0,649 & 7,022 \\
\hline
\end{tabular}

Fonte: dados da pesquisa.

Os coeficientes de caminho indicam quanto um constructo se relaciona com outro; observa-se que todos os constructos apresentaram relação positiva em relação aos valores de $\beta$. Segundo Hair, Hult, Ringle e Sarstedt (2013), valores variam de $-1,0 \mathrm{a}+1,0$, valores próximos de +1.0 indicam relação positiva muito forte entre dois constructos e valores próximos de $-1,0$ indicam relação negativa ou baixa. Próximos de zero indicam relações fracas. Na Tabela 5, a relação entre os constructos e os valores de $\beta$, a relação entre capital intelectual e capacidade absortiva apresentou o valor mais representativo próximo de +1 .

A relação entre capacidade absortiva e inovação, bem como de capital intelectual e inovação também apresentaram relação positiva. Para que o Beta seja aceito deve-se testar a relação causal entre dois constructos e verificar se ela é significante ou não. Assim, utiliza-se o teste t de Student, onde valores acima de 1,96 são considerados significantes a $5 \%$ ou 0,05 , isto é, os constructos são relacionados (Hair, Babin, Money \& Samouel 2005). A Tabela 5 mostra que todos os valores que testaram a relação de causa entre os constructos apresentam-se dentro dos parâmetros propostos por Hair, Babin, Money e Samouel (2005), o que confirma as hipóteses propostas nesta pesquisa. 
Tabela 6 - Análise das hipóteses

\begin{tabular}{|l|l|c|}
\hline \multicolumn{1}{|c|}{ Hipóteses } & \multicolumn{1}{|c|}{ Situação } \\
\hline H1 & Capital intelectual está relacionado positivamente com a inovação & Suportada \\
\hline H2 & Capacidade absortiva está relacionada positivamente com a inovação & Suportada \\
\hline H3 & $\begin{array}{l}\text { Capital intelectual está relacionado positivamente com a capacidade } \\
\text { absortiva }\end{array}$ & Suportada \\
\hline
\end{tabular}

Fonte: dados da pesquisa.

\section{DISCUSSÃO DOS RESULTADOS E CONSIDERAÇÕES FINAIS}

O objetivo desta pesquisa foi propor e analisar um Modelo de Administração Estratégica do Capital Intelectual a partir de práticas da capacidade absortiva como potencializadora de inovação. A partir dos dados coletados verificou-se que segundo as percepções dos gestores o capital intelectual torna-se um propulsor da inovação, e que as práticas da capacidade absortiva possuem influência nesta relação, o que confirma a proposição do Modelo.

Dessa forma, o modelo proposto auxiliou a compreender a capacidade absortiva como propulsora da relação entre o capital intelectual e a inovação. Observa-se que, segundo os gestores, a empresa pesquisada desenvolve práticas de administração estratégica do capital intelectual e que por meio destas práticas peculiares ela direciona os colaboradores e os seus stakeholders para a promoção de uma cultura de inovação. Pode-se citar como exemplos de práticas observadas em relação ao capital intelectual: o estímulo à criatividade; desenvolvimento do nível de escolaridade dos colaboradores; desenvolvimento de competências; ambiente propício para promoção de inovação nas tarefas; implantação de programas de sugestões; melhorias estruturais baseadas em tecnologias; mecanismos de controle de desperdício; busca por novos clientes; clientes satisfeitos; construção de uma relação estável com os clientes; e reputação da empresa. O questionário investigou essas práticas e proporcionou a compreensão sobre rotinas organizacionais capazes de propiciar a administração estratégica do capital intelectual e proporcionar a capacidade de inovar.

Com base nas variáveis quantitativas observouse que o capital intelectual pode ser desenvolvido por meio da capacidade absortiva e potencializar a inovação. As práticas evidenciadas nas variáveis da pesquisa que estão relacionadas ao desenvolvimento da capacidade absortiva e que podem promover o capital intelectual e potencializar a inovação são: assimilação de novas tecnologias; capacidade de utilizar o conhecimento existente internamente em seus colaboradores; realização de benchmarking; aplicação de conhecimentos técnicos e desenvolvimento de patentes.

A pesquisa ainda apontou as práticas que a empresa desenvolve para promoção da inovação, quais sejam: o desenvolvimento de novos produtos; melhorias nos produtos existentes; aplicação de ideias nas melhorias dos produtos; melhorias nos métodos de produção; utilização de novas tecnologias; cultura direcionada para inovação e desenvolvimento do comportamento intraempreeendedor.

A capacidade da empresa em mobilizar e criar ativos de conhecimento no campo estrutural, humano e relacional fomenta a melhoria e inovação de processos, produtos e relacionamentos. A pesquisa também demonstrou que a mobilização dos ativos de conhecimento e sua transformação em inovação devem-se, em parte, à capacidade absortiva da empresa. A capacidade de assimilar os conhecimentos novos ou já existentes e transformá-los em novos conhecimentos, ideias e produtos contribui para a transformação do capital intelectual em inovações. Sugere-se, com base nos dados analisados, que empresas que possuem a administração estratégica do capital intelectual, bem como a capacidade de absorção possam potencializar a inovação, alcançando diferencial competitivo.

Como limitações da pesquisa pode-se mencionar o fato de o modelo apresentado ter sido aplicado a gestores que possuem uma percepção específica baseada na realidade da empresa onde trabalham. Também, o fato de o corte da pesquisa ter sido transversal, o que pode apresentar outras influências relativas ao contexto organizacional, no qual a continuidade da investigação em diferentes momentos poderia permitir uma análise diferenciada a partir da percepção dos respondentes.

Como sugestões de pesquisas futuras, sugere-se a aplicação do modelo proposto a uma amostra maior, como, por exemplo, de nível estadual ou até mesmo nacional, buscando compreender se empresas de setores estáveis, que não demandam inovações, possuem ações estratégicas direcionadas para o desenvolvimento do capital intelectual e da inovação. Sugere-se, também, a replicação do instrumento de pesquisa em uma amostra de setores mais dinâmicos e intensos em inovação, pois se acredita que em tais 
ambientes se exija das empresas uma maior capacidade absortiva, sendo esta condição necessária para o desenvolvimento de inovações e respostas rápidas ao mercado competitivo.

O modelo proposto e avaliado quantitativamente confirmou que a capacidade absortiva e o capital intelectual influenciam positivamente a geração de inovação pela organização, configurando-se como uma nova proposta de promoção do capital intelectual para as empresas e uma nova abordagem teórica para a discussão.

Dessa forma, a presente pesquisa traz como contribuição a comprovação empírica de que o capital intelectual pode ser promovido a partir de práticas relativas à capacidade absortiva potencializando a inovação. $\mathrm{O}$ estudo apresentou a existência da relação entre os constructos pesquisados, proporcionando a visualização de práticas de gestão que são capazes de impulsionar a inovação nas organizações. A pesquisa pretende contribuir em um campo até então não explorado teórica e empiricamente, proporcionando a visualização de novos horizontes para pesquisas relacionadas ao tema inovação.

Propõe-se retomar a discussão para um tema muito investigado, mas ainda com espaços para contribuições teóricas e empíricas em relação ao objetivo deste artigo: o "olhar" de rotinas organizacionais. Neste "olhar", sugere-se que a construção de novas rotinas possa possibilitar o desenvolvimento da capacidade absortiva das empresas e, consequentemente, ser um caminho para uma administração estratégica eficaz do capital intelectual.

\section{REFERÊNCIAS}

Acedo, F. J., Barroso, C., \& Galan, J. L. (2006). The resource-based theory. Dissemination and main trends. Strategic Managament Journal, 27, 621636.

Almeida, P. (2008). Inovação sem inteligência é apenas criatividade sem objetivo. Agência Sebrae. Recuperado em 24 março, 2013, de http://www.agenciasebrae.com.br/

Associação Brasileira de Celulose e Papel. (2013). Papel. Recuperado em 05 maio, 2013, de http://www.bracelpa.org.br/web/pt/nossosprodutos/papel.htm

Barney, J. B. (2001). Is the resource-based "view" a useful perspective for strategic management research? Yes. Academy of Management Review, $26,41-56$.
Beije, P. (1998). Technological Change in the Modern Economy. London: Edward Elgar Publishing Limited.

Camisón, C., \& Forés, B. (2010). Knowledge absorptive capacity: New insights for its conceptualization and measurement. Journal of Business Research, 63 (7), 707-715.

Carbone, P., Brandão, H., Leite, J. B., \& Vilhena, R. M. (2005). Gestão por competências e gestão do conhecimento. Rio de Janeiro. Ed. FGV.

Cohen, J. (1992). A power primer. Psychological bulletin, 112 (1), 155 .

Cohen, W. M., \& Levinthal, D. A. (1989). Innovation and learning: the two faces of R\&D. The Economic Journal, 89, 569-596.

Dias, M. F. P., \& Pedrozo, E. A. (2012). Desenvolvimento sustentável nas inovações tecnológicas da indústria alimentícia Brasileira: em qual estágio estamos? Organizações Rurais \& Agroindustriais, 14 (3), 297-311.

Dumay, J., \& Garanina, T. (2013). Intellectual capital research: a critical examination of the third stage. Journal of Intellectual Capital, 14 (1), 10-25.

Edvinsson L., \& Malone, M. S. (1998). Capital intelectual: descobrindo o valor real de sua empresa pela identificação de seus valores internos. São Paulo: Makron Books.

Edvinsson, L. (2012). IC 21 - Reflections from 21 years of IC practice and theory. Journal of Intellectual Capital, 14, 1-11.

Eisenhardt, K. M., \& Santos, F. M. (2002). Knowledge-based view: anew theory of strategy? In: M. Earl. Knowledge management strategies: towards a taxonomy. Journal of Management Information Systems, 18, (1) Summer.

Flatten, T. C., Engelen, A., Zahara, S. A., \& Brettel, M. (2011). A measure of absorptive capacity: scale development and validation. European Management Journal, 29 (2), 98-116.

Freeman, C., \& Soete, L. (2008). A economia da inovação industrial. Campinas: Ed. Unicamp.

Gracioli, C., Godoy, L. P., Lorenzett, D. B., \& Godoy, T. P. (2012). Capital intelectual: uma ferramenta inovadora na busca por vantagens competitivas DOI: 10.5773/rai. v9i4. 778. RAI: revista de administração e inovação, 9 (4), 96-120. 
Hair, J. F. Jr., Babin, B., Money, A. H., \& Samouel, P. (2005). Fundamentos de métodos de pesquisa em administração. Porto Alegre: Bookman.

Hair, J. F. Jr., Hult, G. T. M., Ringle, C., \& Sarstedt, M. (2013). A primer on partial least squares structural equation modeling (PLS-SEM). SAGE Publications, Incorporated.

Hair, J. F. Jr., Ringle, C. M., \& Sarstedt, M. (2011). PLS-SEM: Indeed a silver bullet. The Journal of Marketing Theory and Practice, 19 (2), 139-152.

Henseler, J., \& Sarstedt, M. (2013). Goodness-of-fit indices for partial least squares path modeling. Computational Statistics, 28 (2), 565-580.

Henseler, J., Ringle, C., \& Sinkovics, R. (2009). The use of partial least squares path modeling in international marketing. Advances in International Marketing (AIM), 20, 277-320.

Hitt, M., Ireland, R. D., \& Hoskisson, R. E. (2008). Administração estratégica. Rio de Janeiro: Pioneira Thomsom Learning.

Ienciu, N. M., \& Matis, D. (2011). A theoretical framework of intellectual capital. International. Journal of Business Research, 11 (2).

Lane, P. J., Koka, B. R., \& Pathak, S. (2006). The reification of absorptive capacity: a critical review and rejuvenation of the construct. Academy of Management Review, 31 (4), 833-863.

Liu, C. L. E. (2012). An investigation of relationship learning in cross-border buyer-supplier relationships: the role of trust. International business review, 21 (3), 311-327.

Machado, R. E., \& Fracasso, E. M. (2012). A Influência dos Fatores Internos na Capacidade Absortiva e na Inovação: Proposta de um Framework. Artigo apresentado no Simpósio da Gestão da Inovação Tecnológica, 27., Salvador: Anpad.

Malek, J., \& Breggar, M. (2001). The new R\&D Paradigm. Pharmaceutical Executive, 21 (2), 78-86.

Malhotra, N. (2012). Pesquisa de marketing: uma orientação aplicada. 6. ed. Porto Alegre: Bookman.

Maroco, J. (2007). Análise estatística com a utilização do SPSS. 3. ed. Lisboa: Silabo.

Mateos-Aparicio, G. (2011). Partial least squares (PLS) methods: Origins, evolution, and application to social sciences. Communications in StatisticsTheory and Methods, 40 (13), 2305-2317.

Murovec, N., \& Prodan, I. (2009). Absorptive capacity, its determinants, and influence on innovation output: Cross-cultural validation of the structural model. Technovation, 29 (12), 859-872.

Nodari, F. (2013). A relação entre o compartilhamento de conhecimento e o desempenho organizacional, mediada pela capacidade absortiva. $144 \mathrm{f}$. Dissertação de Mestrado em Administração não publicada, Pontifícia Universidade Católica do Rio Grande do Sul, Porto Alegre.

Nunnally, J. C., \& Bernstein, I. H. (1994). Psychometric theory. New York: MGraw-Hill.

Rogers, E. M. (1962). Diffusion of Innovations. New York: Free Press.

Santos, D. F. L., Basso, L. F. C., \& Kimura, H. (2012). A estrutura da capacidade de inovar das empresas brasileiras: uma proposta de construto. Revista de Administração e Inovação, 9 (3), 103-128.

Schumpeter, J. A. (1997). Teoria do desenvolvimento econômico: uma investigação sobre lucros, capital, crédito, juro e o ciclo econômico. Tradução M. S. Possas. São Paulo: Nova cultural. (Obra original publicada em 1934).

Stewart, T. A. (1998). Capital Intelectual. A Nova Vantagem Competitiva das Empresas. Rio de Janeiro: Ed. Campus.

Stoeckicht, I. P. (2012). Gestão estratégica do capital intelectual orientado à inovação em empreendimentos de engenharia civil. Tese de Doutoramento em Tecnologia da Construção, Universidade Federal Fluminense, São Paulo.

Subramaniam, M., \& Youndt, M. A. (2005). The influence of intellectual capital on the types of Innovative capabilities. Academy of Management Journal, 48 (3), 450-463.

Sveiby, K. E. (1989). The invisible balance sheet. Stockholm: Affarfgarblen.

Sveiby, K. E. (1997). The new organizational wealth: managing and measuring knowledge-based assets. Berrett-Koehler Publishers, San Francisco.

Tabachnick, B., \& Fidell, L. (2001). Using multivariate statistics. 4. ed. Boston: Allyn and Bacon. 
Tidd, J., Bessant, J., \& Pavitt, K. (1997). Managing Innovation: integrating technological, market and organizational change. London: John Wiley \& Sons Ltda.

Tidd, J., Bessant, J., \& Pavitt, K. (2005). Gestão da inovação. Integração de mudanças Tecnológicas, de mercado e organizacionais. Lisboa: Monitor.

Tidd, J., Bessant, J., \& Pavitt, K. (2008). Gestão da inovação. 3. ed. Porto Alegre: Bookman.

Utterback, J. M. (1971). The process of technological innovation within the firm. Academy of Management Journal, 14 (1), 75-88.

Wang, C. L., \& Ahmed, P. K. (2007). Dynamic capabilities: A review and research. International Journal of Management Reviews, 9, 31-51.
Wegner, D., \& Maehler, A. E. (2010). Capital social e capacidade absortiva: influências no desempenho de empresas participantes de redes interorganizacionais. Artigo apresentado no VI Encontro de Estudos Organizacionais da ANPAD. ENEO 2010, Florianópolis, SC.

Zahra, S. A., \& George, G. (2002). Absorptive capacity: A review, reconceptualization, and extension. Academy of Management Review, 27 (2), 185-203.

Zen, A. C., Dalmoro, M., Fensterseifer, J. E., \& Wegner, D. (2013). O Desenvolvimento de Recursos em Redes Interorganizacionais e o Processo de Internacionalização: O Caso Wines of Brasil. Revista Ibero-Americana de Estratégia, 12(1), 107-130. 